International Journal of Engineering, Science and Technology

Vol. 2, No. 1, 2010, pp. 80-91
INTERNATIONAL

JOURNAL OF

ENGINEERING,

SCIENCE AND

TECHNOLOGY

Www.ijest-ng.com

(C) 2010 MultiCraft Limited. All rights reserved

\title{
Flow field development in a direct injection diesel engine with different manifolds
}

\author{
Benny Paul $^{1 *}$, V. Ganesan ${ }^{2}$ \\ ${ }^{1,2}$ Internal Combustion Engines Laboratory, Department of Mechanical Engineering, Indian Institute of Technology Madras, Chennai 600 036, India \\ "Corresponding author: e-mail:benny.mace@gmail.com
}

\begin{abstract}
This paper reports a study on the effect of helical, spiral, and helical-spiral combination manifold configuration on air motion and turbulence inside the cylinder of a Direct Injection (DI) diesel engine motored at $3000 \mathrm{rpm}$. Three-dimensional model of the manifolds and the cylinder is created and meshed using the pre-processor GAMBIT. The flow characteristics of these engine manifolds are examined under transient conditions using Computational Fluid Dynamics (CFD) code STAR-CD. The predicted CFD results of mean swirl velocity of the engine at different locations inside the combustion chamber at the end of compression stroke are compared with experimental results available in the literature. We also compared the volumetric efficiency of the modeled helical manifold. The results obtained showed reasonably good agreement with the measured data given in the literature. Further, this paper discusses the predicted flow structure, swirl velocity and variation of turbulent energy inside the cylinder with different manifold. Comparisons of volumetric efficiency with different manifold configuration at $3000 \mathrm{rpm}$ speed are also presented. The turbulence is modeled using RNG k- $\varepsilon$ model. It is observed that helical-spiral manifold gives the maximum swirl ratio inside the cylinder than helical manifold. But volumetric efficiency observed is less for helical-spiral manifold engine. Swirl inside the engine is important for diesel engine. Hence, for better performance a helical-spiral inlet manifold configuration is recommended.
\end{abstract}

Keywords: Flow structure, spiral manifold, helical manifold, helical-spiral combined manifold, turbulence, swirl, CFD, Diesel engine

\section{Introduction}

Flow of air through the manifold and mixing of the fuel with air inside the cylinder is more important in the case of diesel engine because these factors, directly affect the volumetric efficiency, combustion performance, output and emission levels of the engine. Control of flow through the manifold is critical for meeting the emission regulations and fuel economy requirements. Parameters like engine speed, manifold and combustion chamber configuration (Chen et al., 1998) directly influence the swirl in DI diesel engines and subsequently it plays a vital role in mixing air and fuel inside the cylinder. Optimization of swirl becomes an important aspect in the design of intake systems of diesel engines.

Nowadays, with the availability of powerful computers, the CFD prediction methods for in-cylinder flow of IC engines have become popular. They can give very useful information regarding the flow pattern and has the potential to reduce the total development time of the intake system of an IC engine. Engine manufactures require precise engine design to bring the end product to the market in a short time period and hence CFD codes play an important role in IC engine design.

Borgnakke (1981) presented a flow model to predict the swirl vortices and turbulence in an open chamber cup-in-piston engine. The work was compared with experimental data over a range of engine intake manifold and combustion chamber configurations. Lot of work has been done on engine flow and on the parameters that affect the turbulence, performance and emissions in a DI diesel engine. Kim et al. (1999) carried out the modeling of flow distribution in exhaust manifold. Modifications were made on the inlet and exhaust manifolds based on the results obtained. They also conducted experiments and validated the performance and emissions of the engine. Akira et al. (1990) presented an experimental analysis for turbulence inside the combustion chamber of direct injection diesel engine. The study provided a better understanding of the effects of piston bowl shape, engine speed, 
manifold shape and compression ratio on the flow fields in a DI diesel engine. Chiavola et al. (2001) conducted a study on the flow behavior in intake and exhaust system of an internal combustion engine and observed that the flow phenomenon in ducts closely affects the volumetric efficiency of the engine.

Many researchers (Brandstatter, 1985; Payri et al., 1996 and Zhu et al. 2005) had conducted experimental / simulation work on flow modeling to study the effect of engine configurations viz piston bowl, valve profile, manifold configurations, inlet manifold duct length, pent roof piston etc. Binachi et al. (2003) and Sridhar et al. (2004) had discussed a study related to the effect of operating parameters in the turbulence and swirl level in DI diesel engine. Flow parameter measurements technique including practical and simulation methods are explained in many research papers, viz, Dent et al. (1974), William et al. (1997) and Auriemma et al. (2003).

From the review of literature, it can be noted that, design of inlet manifold configuration is very important in an IC engine. Hence, this study looks up on the effect of helical, spiral, and helical-spiral combined configuration on the induced mean swirl velocity in the piston bowl at TDC, swirl ratio during suction and compression stroke, turbulent kinetic energy variation and volumetric efficiency at engine speed $3000 \mathrm{rpm}$.

Objective of the present study is:

- Modeling the engine with inlet valve, exhaust valve and manifold

- Effect of inlet manifold configurations on the in-cylinder flow

- Turbulence in a diesel engine under non-firing conditions

- Effect of different (helical, spiral, helical-spiral) inlet manifold configurations on volumetric efficiency, turbulence, and swirl in the engine.

By using the CFD code, flow field can be predicted by solving the governing equations viz., continuity, momentum and energy.

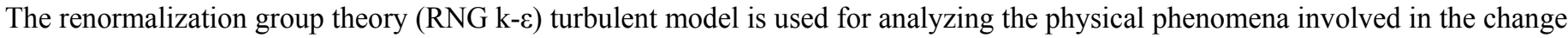
of kinetic energy. In this work, three manifolds (helical, spiral, and helical-spiral combination are considered and in-cylinder flow field investigations are carried out for an engine speed $3000 \mathrm{rpm}$. The simulated tangential velocity normalised with piston speed $(\mathrm{W} / \mathrm{Vp})$ in the bowl at TDC obtained from the model is verified with the available experimental results for the engine geometry having helical manifold. The experimental results are available from the literature (Margary et al., 1990).

\section{Engine and computational details}

The base engine is same for all three manifold configurations CFD analysis. The detailed specification of the base engine selected for the simulation is given in Table 1 . The engine selected is a single cylinder research DI diesel engine with helical inlet manifold and operating characteristics similar to IVECO 8140 DI diesel engine.

Table 1. Geometrical Details of the engine 1

\begin{tabular}{|l|l|l|l|}
\hline Bore & $93 \mathrm{~mm}$ & Inlet valve diameter & $39.7 \mathrm{~mm}$ \\
\hline Stoke & $90 \mathrm{~mm}$ & Exhaust valve diameter & $30 \mathrm{~mm}$ \\
\hline Displacement & 0.611 liters & Maximum inlet valve lift & $9.1 \mathrm{~mm}$ \\
\hline Connecting rod length & $171 \mathrm{~mm}$ & Inlet valve opening IVO) & 80 BDC \\
\hline Bowl entry diameter & $52 \mathrm{~mm}$ & Inlet valve closing & $218^{0}$ ATDC \\
\hline Bumping clearance & $1.2 \mathrm{~mm}$ & Inlet/Exh. valve overlap & 160 \\
\hline Compression ratio & 16 & Engine speed range & $1000-3000 \mathrm{rpm}$ \\
\hline
\end{tabular}

\section{Methodology}

The methodology adopted for the present work is as follows. Flow through the intake manifold is simulated to study the incylinder flow field during non-reacting conditions, which includes the following steps:

- Solid modeling of the intake manifold and cylinder geometry with valves.

- Mesh generation. Solution of the governing equations with appropriate boundary conditions.

- Comparison of the simulated results with the available results in the literature.

The study is expected to explore the potential of using CFD tool for design and optimisation of engine inlet manifold. The commercial CFD code STAR-CD is used for the analysis of flow. The CFD package includes user interfaces to input problem parameters and to examine the results. The code contains three elements

1. Pre-Processor

2. Solver 


\section{Post Processor}

Pre processor mainly involves the creation of basic 3D model, grid generation and fixing of the boundary conditions. Modeling and meshing is done in GAMBIT and is exported to STAR-CD for completing the mesh.

Figure 1 shows the spiral manifold for the flow simulation and Fig 2 shows the helical manifold configuration and Fig. 3 shows the helical-spiral manifold. In this analysis approximately 326672 lakhs of hexahedral structured mesh is created for the manifolds and cylinder.

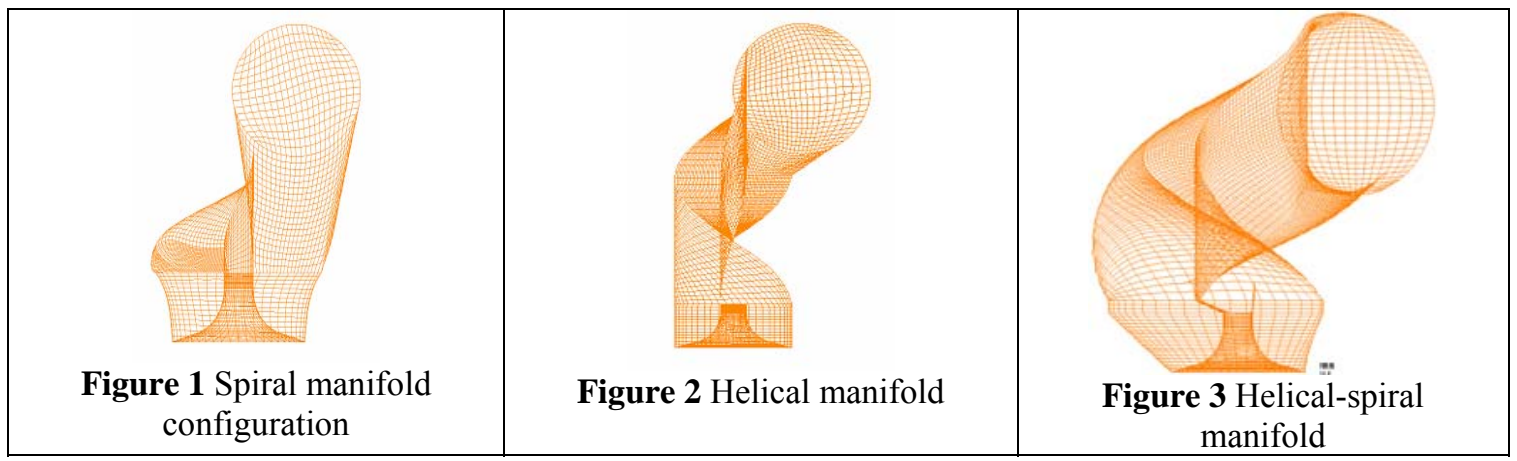

Numerical solution techniques that form the basis of the solver perform the following

1. Approximation of unknown flow variables by means of simple functions

2. Discretisation by substitution of the approximations into governing flow equations and subsequent mathematical manipulations

3. Solution of the algebraic equations

Partial differential equations for conservation of mass, momentum, energy, chemical species, turbulent kinetic energy and its dissipation rate are integrated over individual finite control volumes and the resulting volume integrals are transformed to their surface counterparts. The equations represent an algebraic form of the discretised conservation equations, which are solved using an iterative methodology. The pressure-velocity coupling is achieved using PISO (Pressure Implicit Splitting of Operators) algorithm. The second order differencing scheme MARS (Monotone Advection and Reconstruction Scheme) is used for the present investigation.

Post processor of the code is used for the analyses and display of results are in the following manner:

- Domain geometry and grid display

- Vector plots Line and shaded contour plots

- 2D and 3D surface plots

- Particle tracking

More recently these facilities also include animation for dynamic result display. In addition to graphics, all codes have data export facilities for further manipulation external to the code.

\section{Mathematical model}

Flow through the intake system is treated as compressible and the flow conditions inside the cylinder have been predicted by solving the continuity, momentum, and energy equations (Auriemma et al, 2003 and Versteeg and Malalasekhara 1995). The mass and momentum equation which are used for the solution are given in tensor form as:

$$
\begin{aligned}
& \frac{\partial \rho}{\partial t}+\frac{\partial}{\partial x_{j}}\left(\rho u_{j}\right)=s_{m} \\
& \frac{\partial \rho u_{i}}{\partial t}+\frac{\partial}{\partial x_{j}}\left(\rho u_{j} u_{i}-\tau_{i j}\right)=-\frac{\partial p}{\partial x_{i}}+s_{i}
\end{aligned}
$$


where $t=$ time, $x_{i}=$ Cartesian coordinate, $u_{i}=$ absolute velocity component in direction $x_{\mathrm{i}} \cdot \tau_{i j}=$ stress tensor, $s_{m}=$ mass source, $s_{i}=$ momentum source components.

For the engine analysis where the fluid flow is usually turbulent the variables $u_{i}, \rho$ and other dependent variables including $\tau_{i j}$ assume their ensemble averaged values, giving a relation for the stress tensor as:

$$
\tau_{i j}=2 \mu S_{i j}-\frac{2}{3} \mu \frac{\partial u_{k}}{\partial x_{k}} \delta_{i j}-\bar{\rho} \overline{u_{i}^{\prime} u_{j}^{\prime}}
$$

where $u^{\prime}$ are fluctuations about the ensemble average velocity and the over bar denotes the ensemble averaging process. The rightmost term in the above represents the additional Reynolds stresses due to turbulent motion. These are linked to the mean velocity field through the turbulence models. In the present study RNG k- $\varepsilon$ turbulence model, which is an improvement over standard k- $\varepsilon$ model is employed. The RNG k- $\varepsilon$ model provides a more general and fundamental approach and is expected to yield improved predictions of near wall flows, separated flows, flows in curved geometries and flows that are strained by effects such as impingement or stagnation. In this model more terms appear in the dissipation rate in transport equation, including rate of strain term which is important for treatment of flows in rapid distortion limit such as separated flows and stagnation flows. These

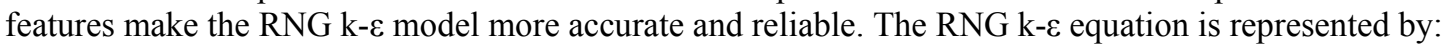

$$
\begin{aligned}
& \frac{\partial(\rho k)}{\partial t}+\operatorname{div}(\rho k U)=\operatorname{div}[\left.\alpha_{k} \mu_{e f f} g r a d k\right] \\
&+2 \mu_{t} E_{i j .} E_{i j}-\rho \varepsilon \\
& \frac{\partial(\rho \varepsilon)}{\partial t}+\operatorname{div}(\rho \varepsilon U)=\operatorname{div}\left[\alpha_{\varepsilon} \mu_{e f f} g r a d k\right] \\
&+C_{1 \varepsilon}^{*} \frac{\varepsilon}{k} 2 \mu_{t} E_{i j .} E_{i j} \\
&-C_{2 \varepsilon} \rho \frac{\varepsilon^{2}}{k}
\end{aligned}
$$

\section{Boundaries and initial conditions}

Constant pressure is used as boundary condition at both the intake and the exhaust manifolds. Attach boundaries are specified on the coincident cell face near the cells above / below the valve. No slip wall boundary condition in conjunction with logarithmic law of wall is used. Walls are considered to be adiabatic.

\section{Grid independence study}

Grid independence test is conducted for the base engine with helical manifold to study the effect of grid density on the predicted results. For this purpose, simulation is conducted with varying grid density from 1 to 4 lakhs / litre. Figure 3 shows the Swirl Ratio (SR) comparison of helical manifold with different grid density and Fig. 4 compares the mass averaged Turbulent Kinetic Energy (TKE) curves for the four grids during the suction and compression. The variation of the SR, TKE and time consumed for one cycle is given in Table 2. The percentage variation between 2 and 3 lakhs grids is $6 \%$ whereas for 4 and 5 lakhs is $1.8 \%$. The time consumed for one cycle is 30 to $40 \%$ higher than 4 lakhs for SR. It is observed that between four lakhs and three lakhs the variation of TKE is $1.5 \%$. Considering the computational cost and time, the grid density of 3 lakhs/ litre is selected. Based on the grid independence test carried out, all the simulation cases are conducted with 3 lakhs/litre cells.

Table 2 Grid independence study

\begin{tabular}{|l|l|l|l|l|l|}
\hline No & SR Variation \% & \multicolumn{1}{|l|}{ TKE Variation \% } & Time Variation \\
\hline Case 1 & Between 1\& 2 lakh /1 & 7 & Between 1\& 2 & 7 & 15 hours \\
\hline Case 2 & Between 2 \& 3 lakh /1 & 6 & Between 2 \& 3 & 4 & 20 hours \\
\hline Case 3 & Between 3 \& 4 lakh /1 & 1.8 & Between 3 \& 4 & 1.5 & 30 hours \\
\hline
\end{tabular}




\section{Mean swirl velocity in the piston bowl at TDC}

Figures 4 to 6 show the radial distribution of mean swirl velocity and (W/Vp) and RMS velocity component normalized with piston speed in the piston bowl at TDC for different manifold configurations at $3000 \mathrm{rpm}$. It is observed that the W/Vp for helicalspiral combined manifold is maximum near the cylinder head $(\mathrm{Z}=3)$ at $3000 \mathrm{rpm}$. The mean swirl velocity component $(\mathrm{W} / \mathrm{Vp})$ normalized with piston speed increases as it moves away from the cylinder axis. The RMS velocity fluctuation observed inside the piston bowl at TDC of compression is less affected by the inlet manifold configurations.

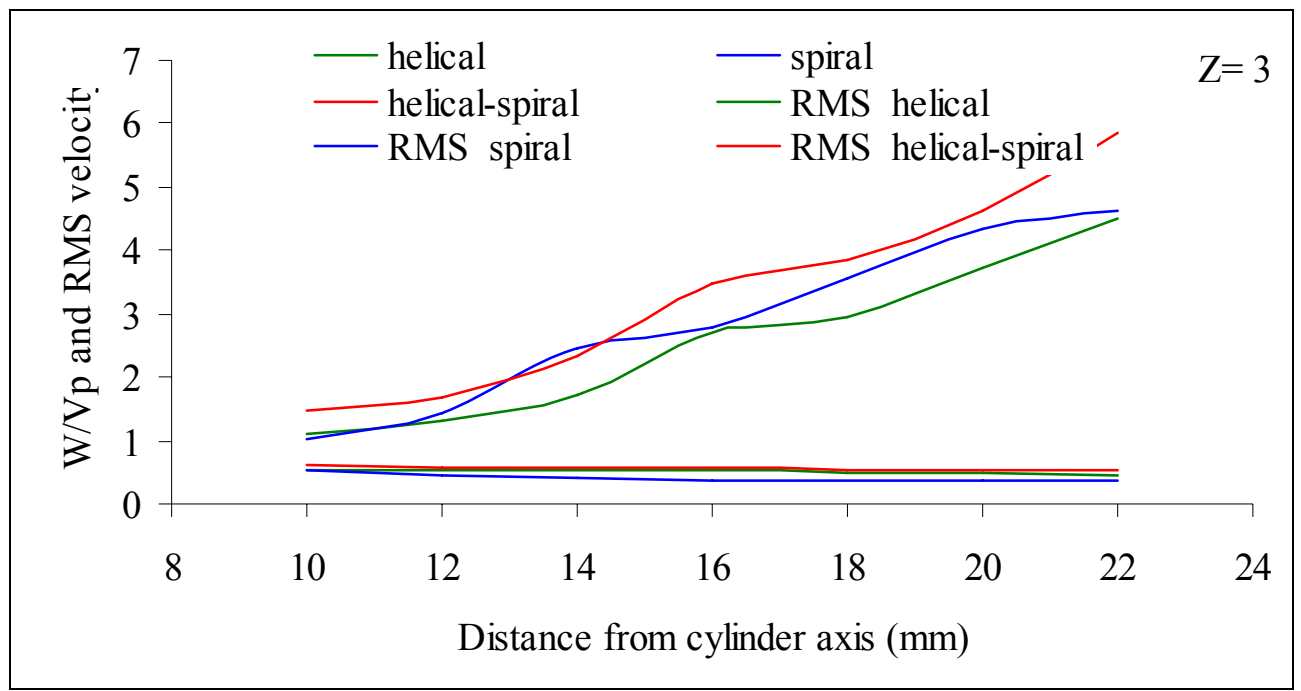

Figure 4 Radial distribution of mean swirl velocity component (W/Vp) and RMS velocity in the piston bowl at TDC and $3000 \mathrm{rpm}$.

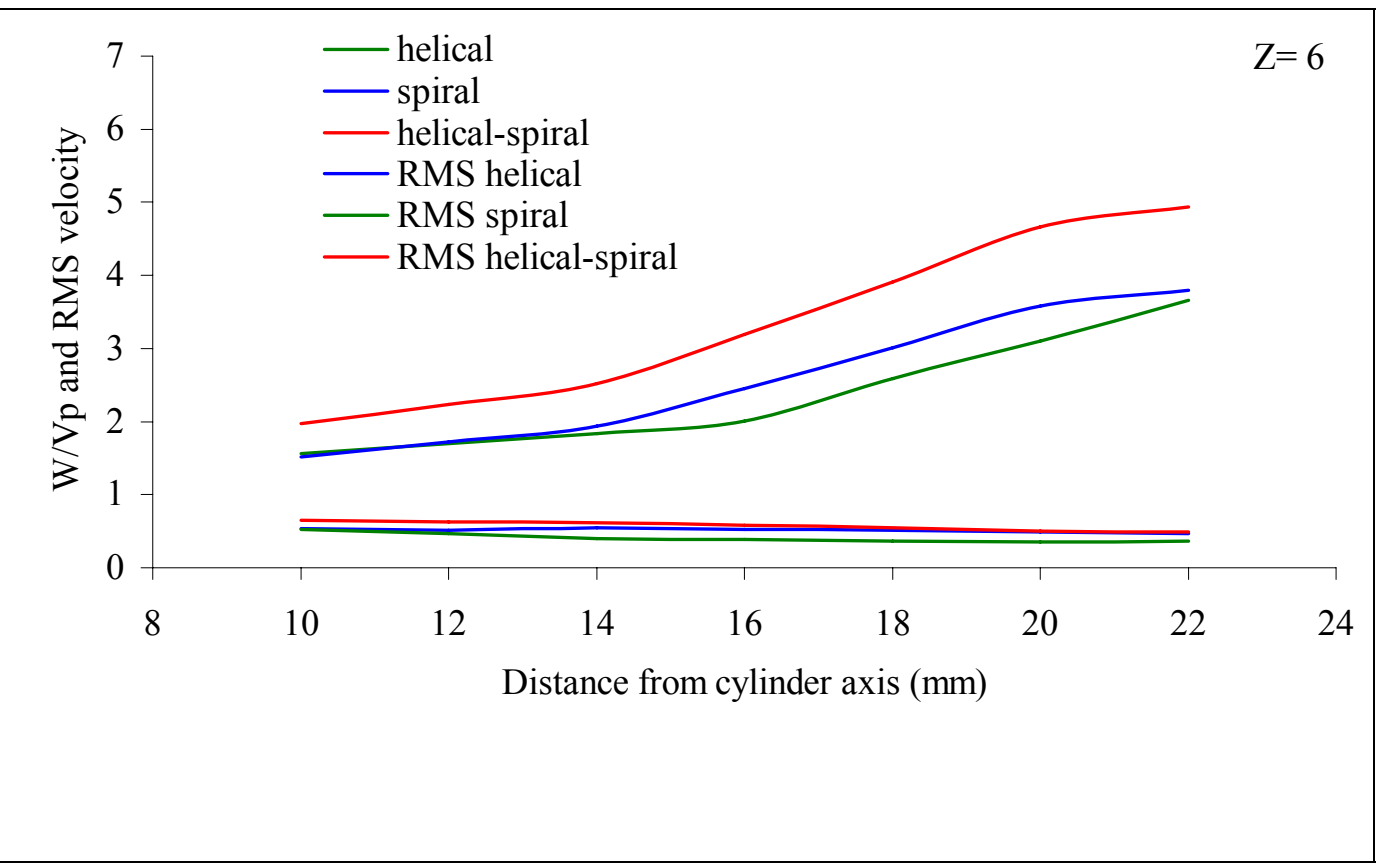

Figure 5 Radial distribution of mean swirl velocity component (W/Vp) and RMS velocity in the piston bowl at TDC and $3000 \mathrm{rpm}$ 


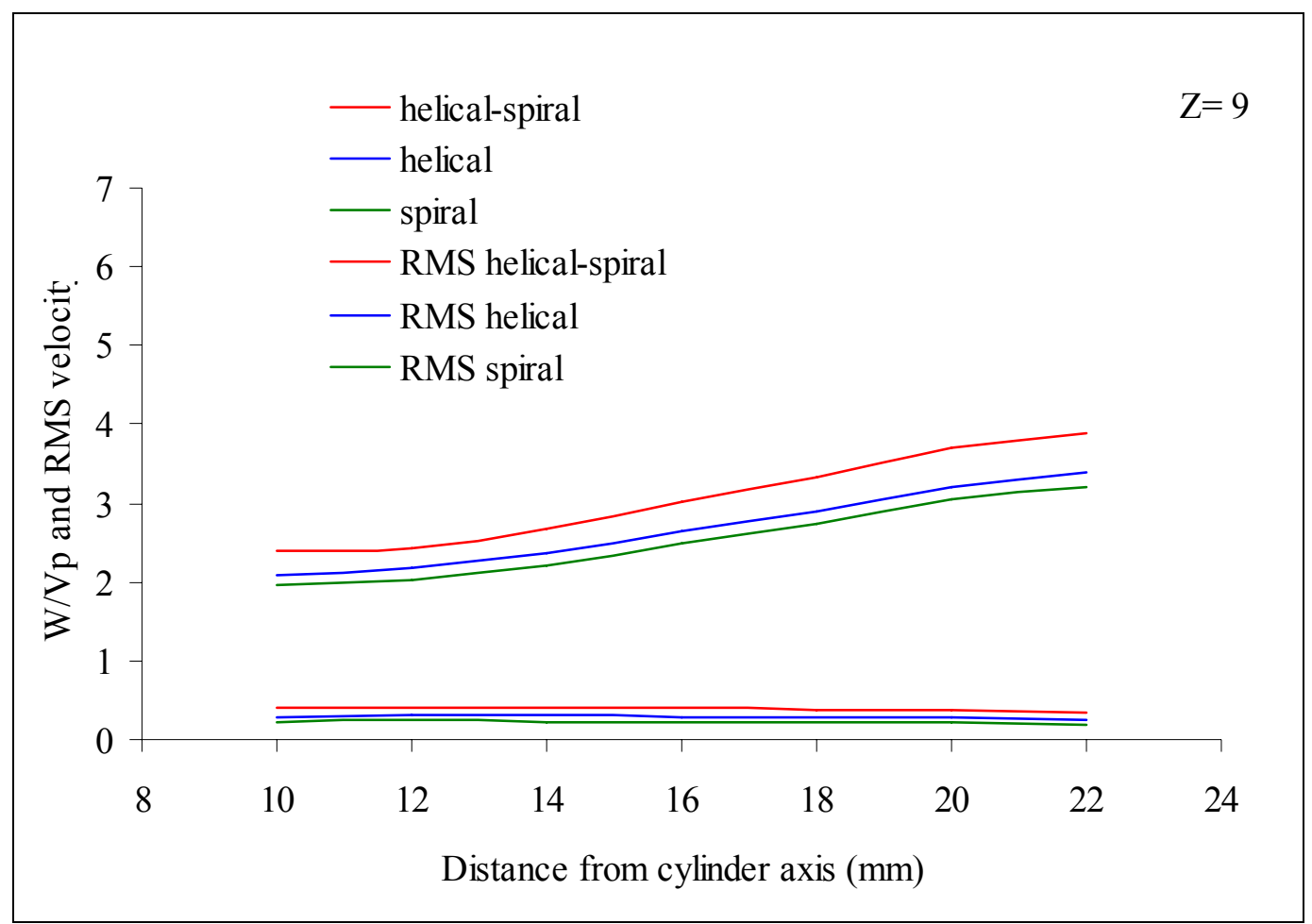

Figure 6 Radial distribution of mean swirl velocity component (W/Vp) and RMS velocity in the piston bowl at TDC and $3000 \mathrm{rpm}$

The flow structure is found to be extremely difficult to analyse because of its complexity inside the cylinder. To aid both, interpretation and explanation it was found useful to assign labels to identify different location on which studies were carried out $(\mathrm{Z}=30,50$ and $70 \mathrm{~mm}$ from cylinder top face) at IVC. Radial distance ' $\mathrm{r}$ ' from the cylinder axis is selected as 10, 15, 20, 25, 30, 35,40 and $45 \mathrm{~mm}$. On these locations the mean swirl velocity (W/Vp) normalized with piston speed plotted. The location is shown in Fig. 7 Figures 8 to 10 present the in-cylinder mean swirl velocity distribution with helical-spiral combined configuration at three planes from cylinder head with engine speed of 1000, 2000 and $3000 \mathrm{rpm}$. In all the figures it is observed that the swirl mean velocity magnitudes are higher close to the wall compared to center. This is again attributed to the manifold configuration, which directs the incoming air towards the wall. Because of swirling action (solid body rotation) fluid particles away from the center moves at a higher velocity as compared to the location near the center in all engine speed. The mean velocity magnitude seems to increase with respect to engine speeds. However, between 2000 and $3000 \mathrm{rpm}$ there is not much of a change.

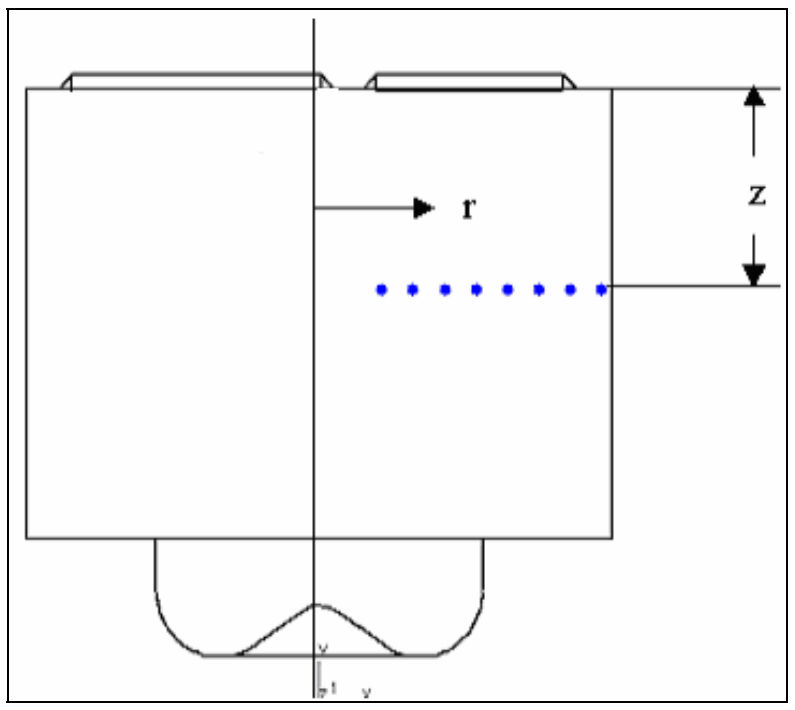

Figure 7 Location of measurement for mean swirl velocity component (W/Vp) at IVC 


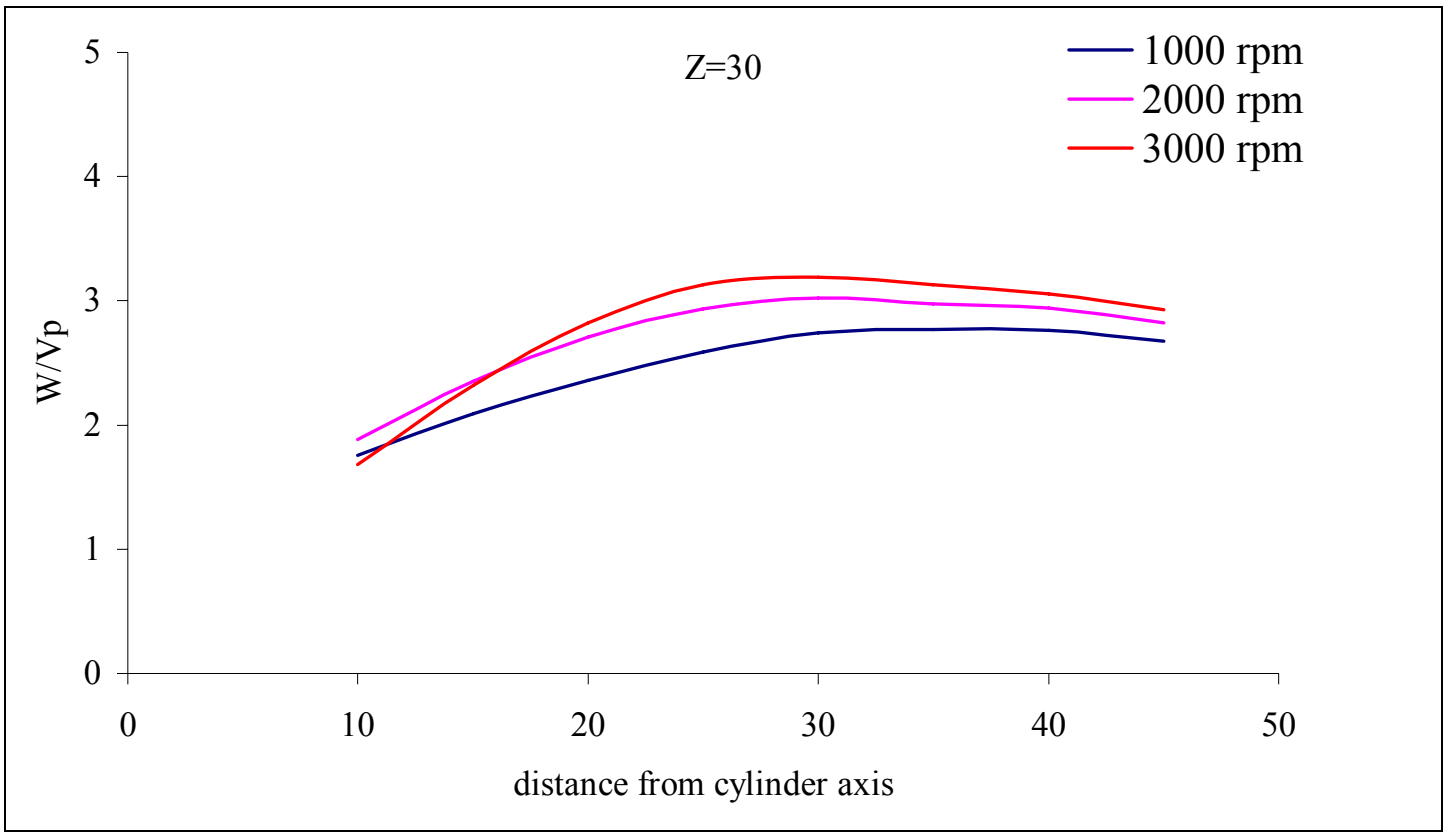

Figure 8 Radial distribution of mean swirl velocity component (W/Vp) in the piston at IVC for different speed with helical-spiral manifold

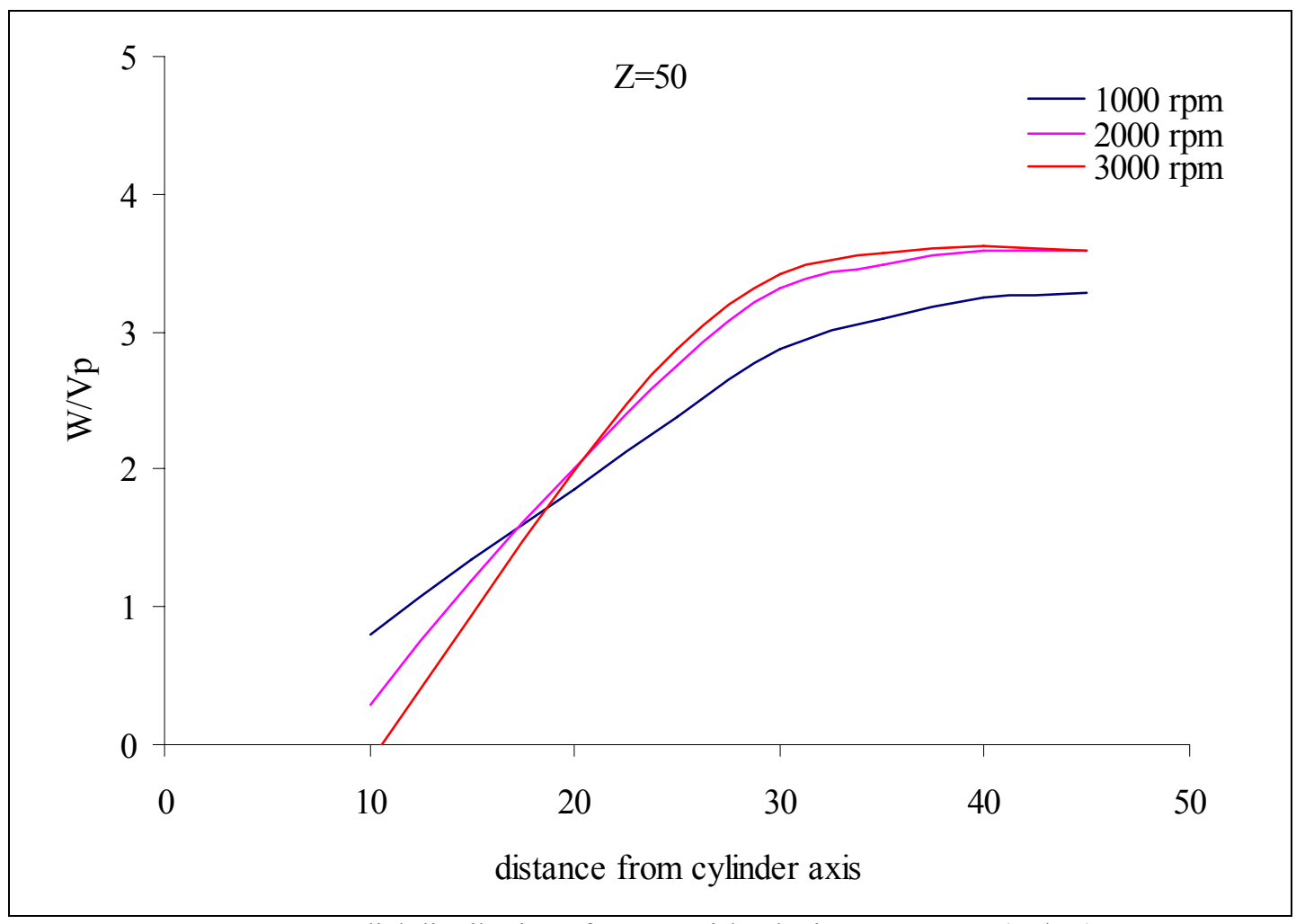

Figure 9 Radial distribution of mean swirl velocity component (W/Vp) in the piston at IVC for different speed with helical-spiral manifold 


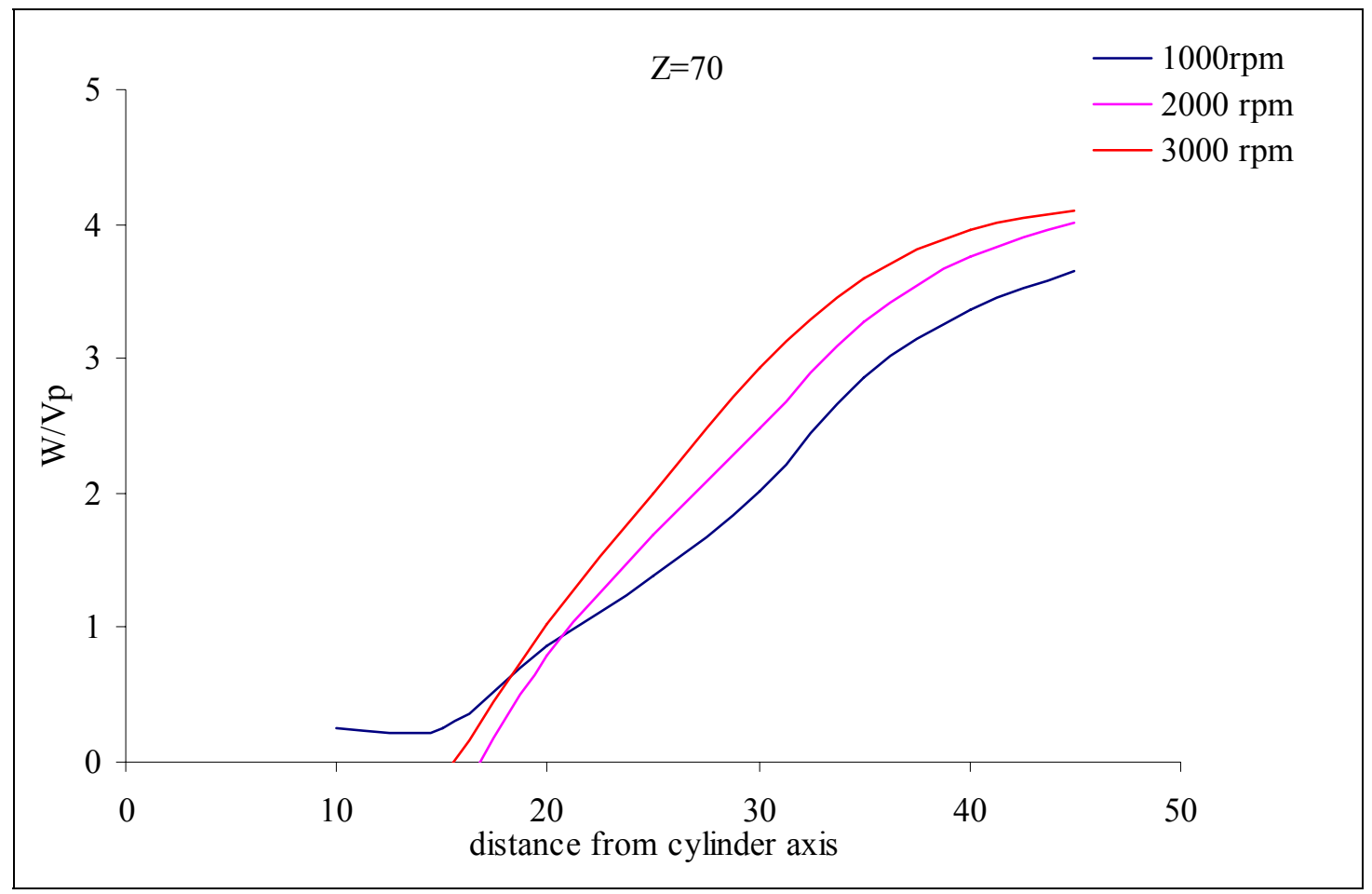

Figure 10 Radial distribution of mean swirl velocity component (W/Vp)

in the piston at IVC for different speed with helical-spiral manifold

\section{Swirl ratio inside the cylinder}

Figure 11 shows the variation of Swirl Ratio (SR) inside the cylinder with respect to crank angle for different manifold configurations at $3000 \mathrm{rpm}$. During the suction stroke, the swirl ratio increases till the maximum valve lift position and gradually decreases till the end of valve closing and again increases at the end of compression stroke. The reason is same, which has been which explained in an earlier section. In the comparison of swirl ratio at $3000 \mathrm{rpm}$, maximum value is obtained for helical-spiral combined manifold configuration over the other two manifolds.

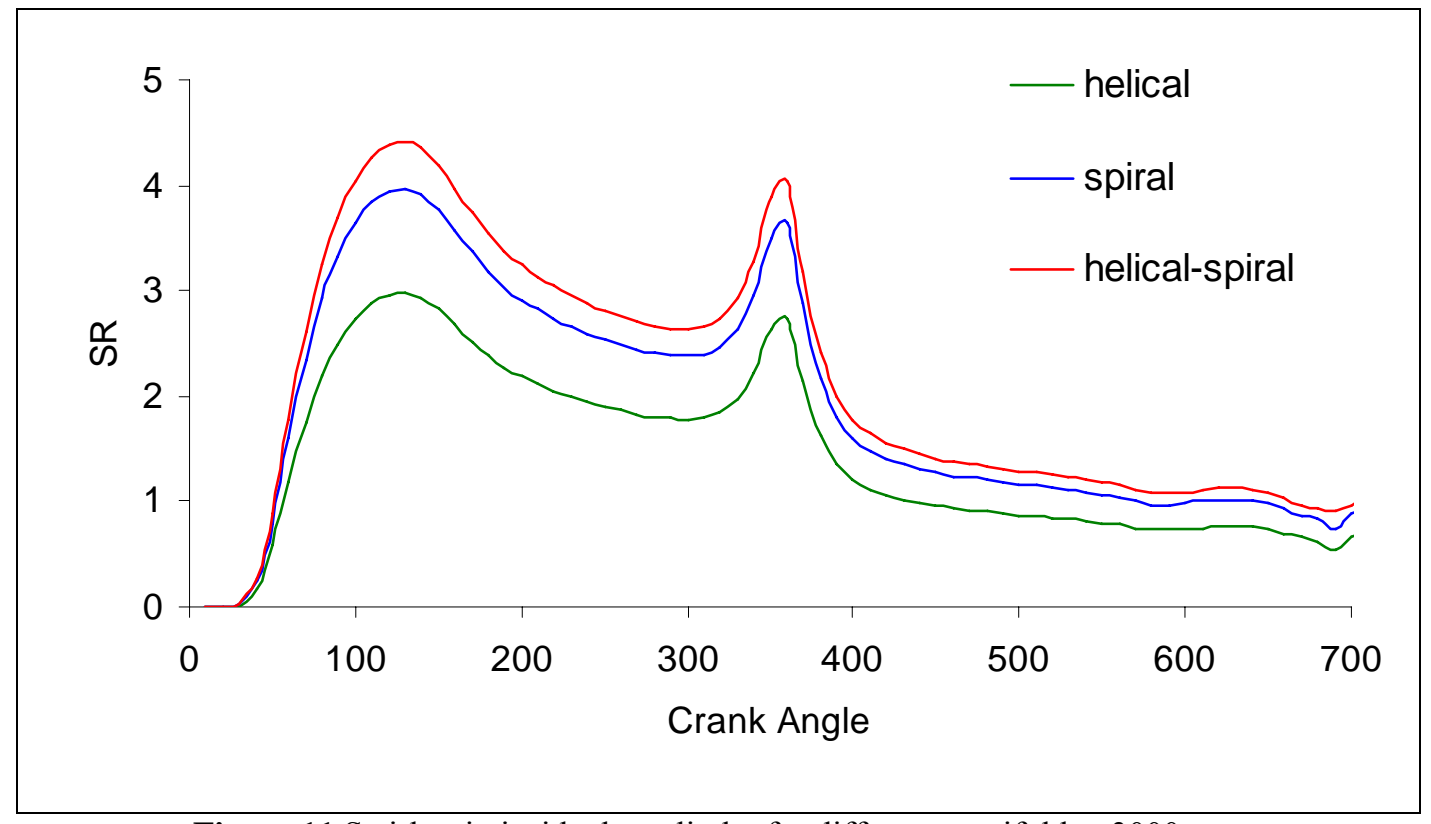

Figure 11 Swirl ratio inside the cylinder for different manifold at $3000 \mathrm{rpm}$ 


\section{Tangential velocity inside cylinder at maximum valve lift}

When the valve is at full open position, the intake flow is maximum towards the cylinder, forming a re-circulation zone below the valve (Figures 12 to 14). In the case of helical-spiral combined manifold the formation of re-circulation zone is observed in many locations. The strength of re-circulation zone provided by spiral and helical configuration are weak.

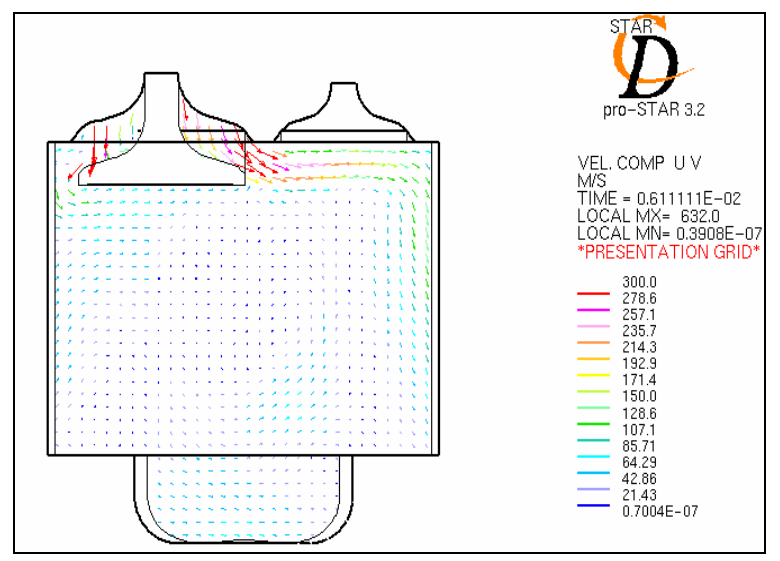

Figure 12 Velocity vector at max. valve lift position for helical manifold

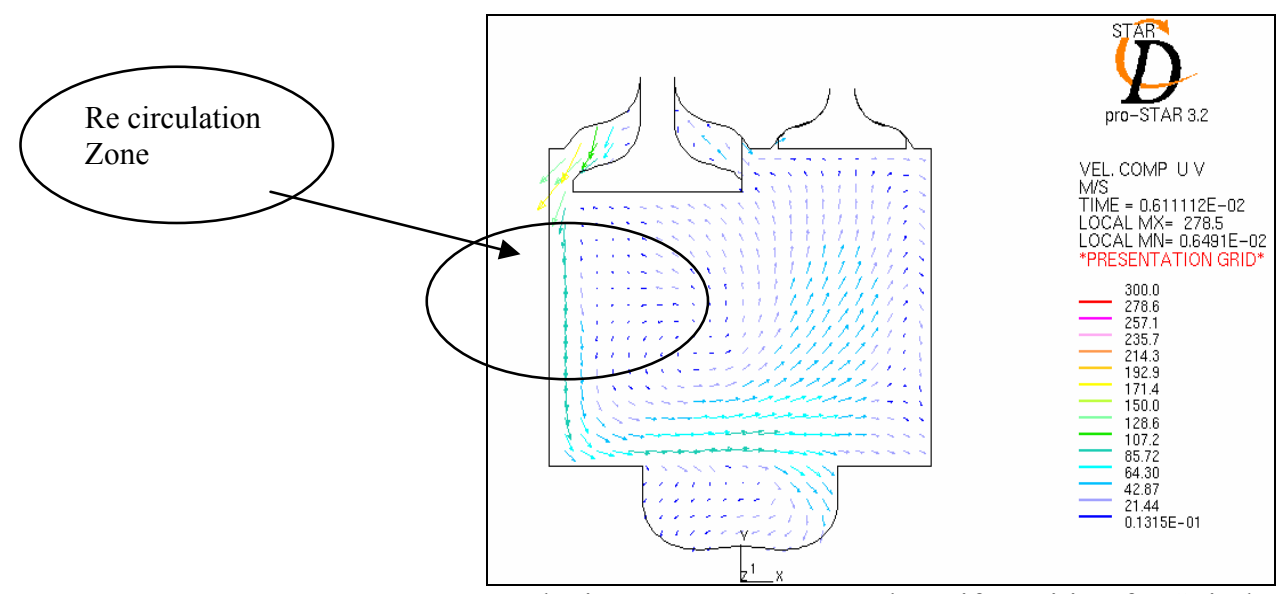

Figure 13 Velocity Vector at Max. Valve Lift Position for Spiral Manifold

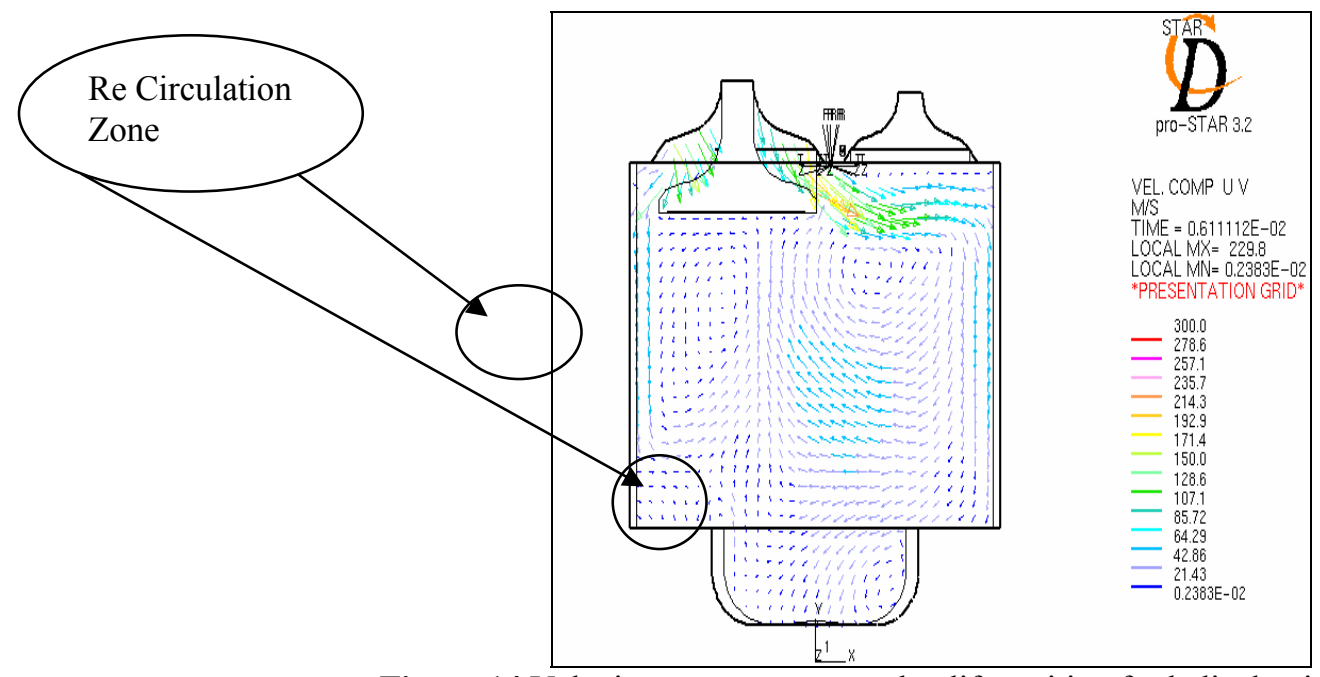

Figure 14 Velocity vector at max. valve lift position for helical-spiral manifold 


\section{Turbulent kinetic energy inside the cylinder}

Figure 15 shows the variation of Turbulent Kinetic Energy (TKE) with crank angle at $3000 \mathrm{rpm}$ for different manifolds. It is observed that the inlet manifold configuration affects the turbulence of the fluid inside the cylinder. It reaches the peak value during the maximum valve open condition. The variation of TKE is probably due to different level of air induced through the inlet manifold. The dissipation of KE is on account of increased fluid motion. Due to this, high SR is observed for helical-spiral combination than other manifolds and low level of TKE as shown in Figure 11.

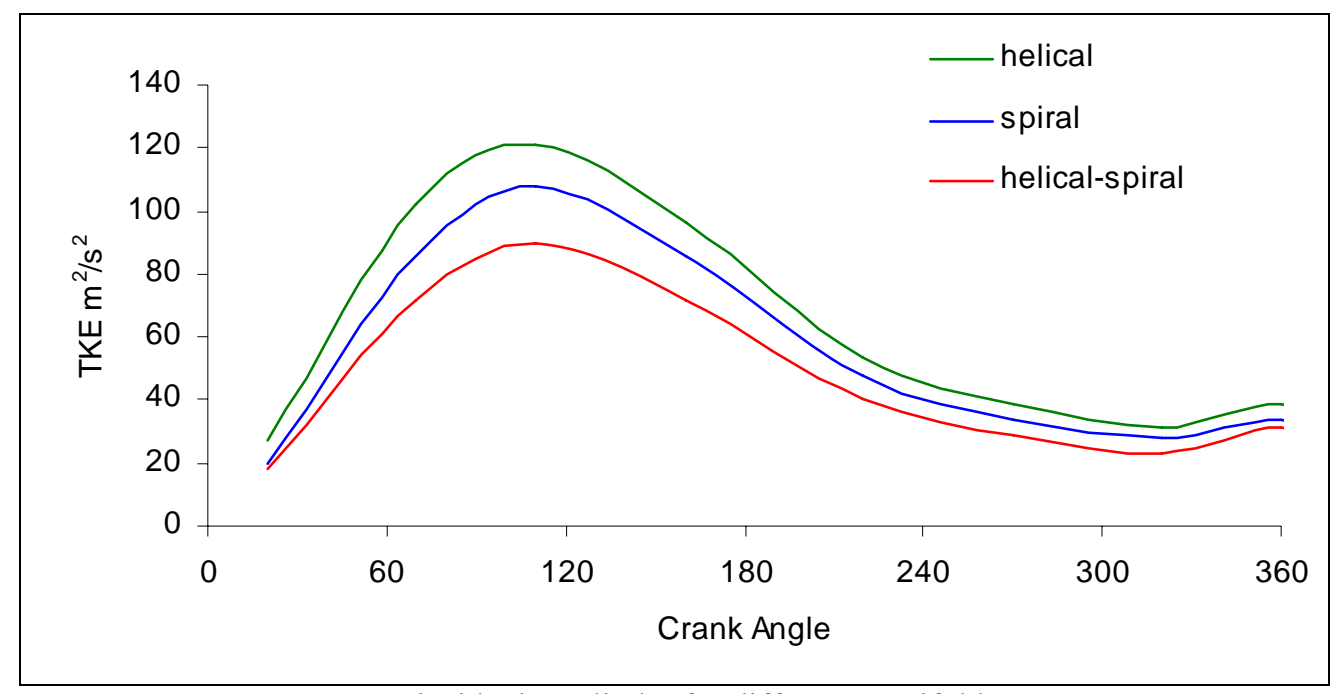

Figure 15 TKE inside the cylinder for different manifold at $3000 \mathrm{rpm}$

Figures 16 to 18 presents the kinetic energy contour at the end of intake stroke for helical, spiral and helical-spiral combination manifold. TKE is higher for helical manifold compared with the other two manifolds at $3000 \mathrm{rpm}$. It is uniformly distributed in the entire cylinder at the beginning of compression stroke for helical-spiral manifold.

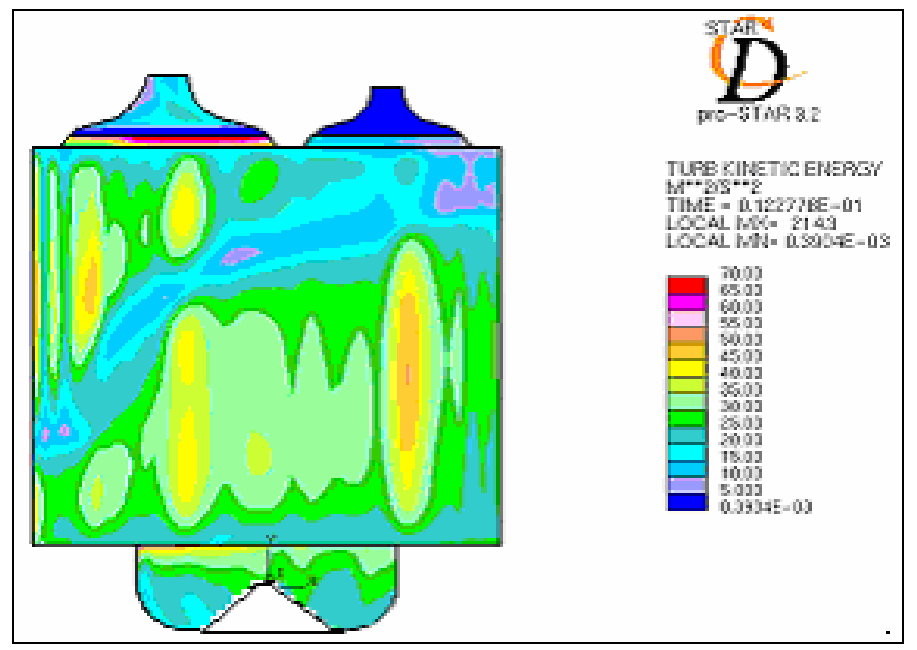

Figure 16 TKE inside the cylinder for helical manifold at the beginning of compression stroke at $3000 \mathrm{rpm}$

\section{Volumetric efficiency}

Figure 19 shows the comparison of volumetric efficiency for different manifolds at $3000 \mathrm{rpm}$. The spiral manifold shows lower value due to the flow restriction than other configurations. Improvement of volumetric efficiency is achieved by helical-spiral combination. 


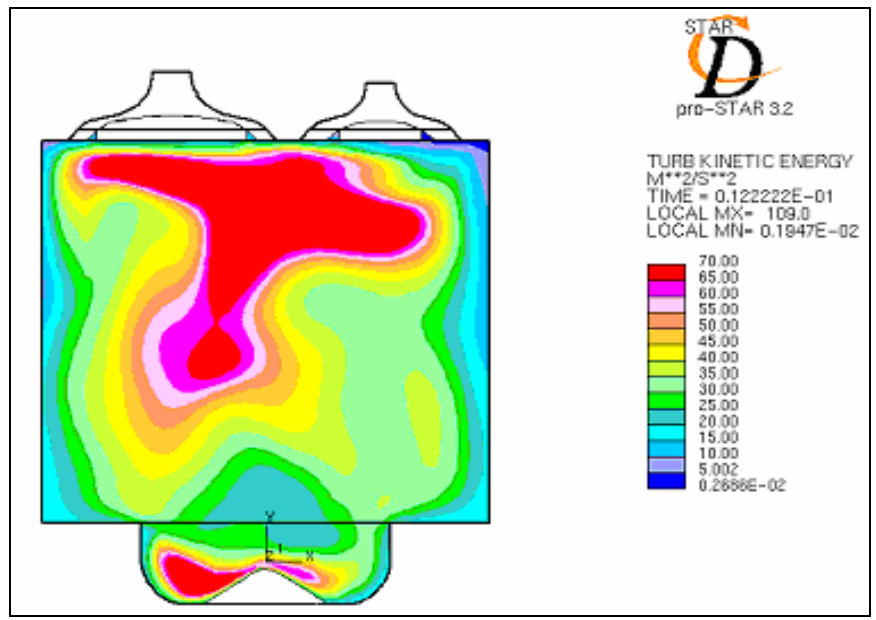

Figure 17 TKE Inside the cylinder for spiral manifold at the beginning of compression stroke at $3000 \mathrm{rpm}$

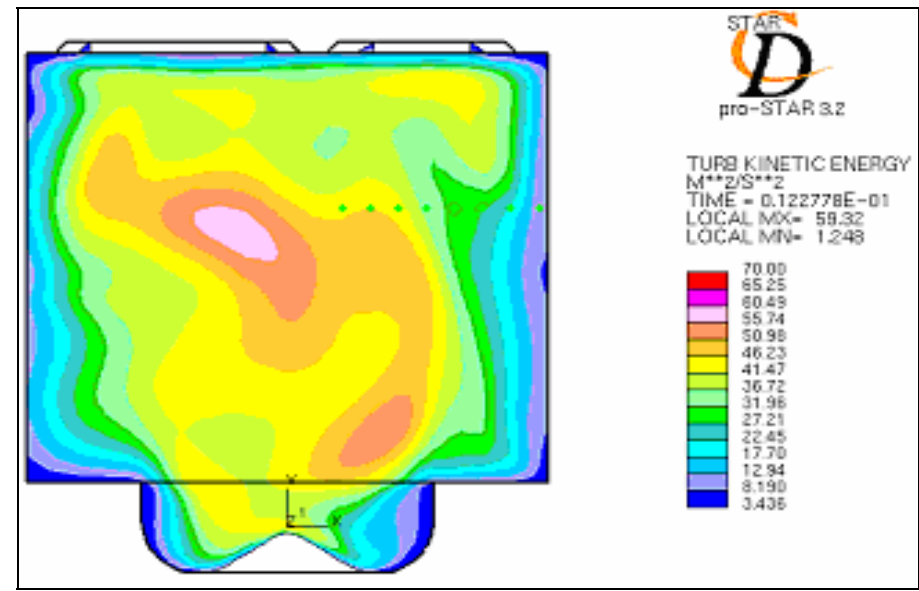

Figure 18 TKE inside the cylinder for helical-spiral manifold at the beginning of compression stroke at $3000 \mathrm{rpm}$

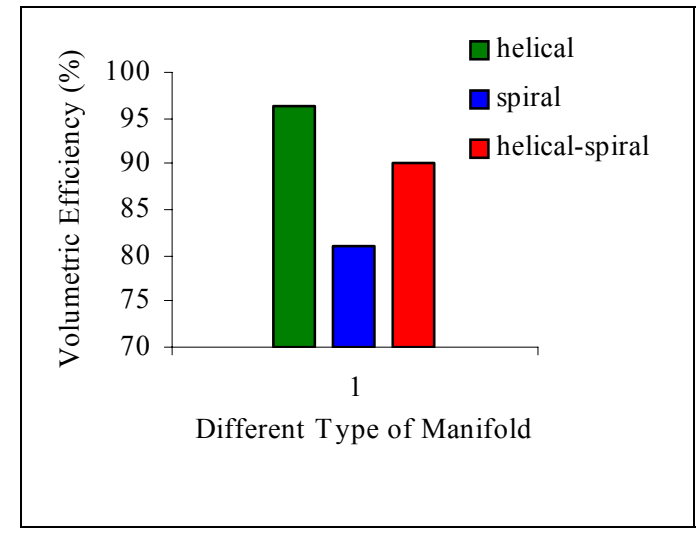

Figure 19 Volumetric efficiency of different manifold configuration at $3000 \mathrm{rpm}$.

\section{Conclusion}

After the analysis of different manifolds in the previous sections, analysis is extended to compare the effect of different manifold configurations on flow structure. The helical-spiral manifold geometry creates higher velocity component $(\mathrm{W} / \mathrm{Vp})$ inside the combustion chamber at the end of compression stroke. Swirl ratio inside the cylinder and turbulent kinetic energy are higher for 
spiral manifold. Volumetric efficiency for the spiral-helical combined manifold is $10 \%$ higher than that of spiral manifold. The summary of the comparison is as follows:

1. Helical-spiral combined manifold creates higher swirl inside the cylinder than spiral manifold.

2. Helical manifold provides higher volumetric efficiency.

3. Helical-spiral combined manifold provides higher mean swirl velocity at TDC of compression.

4. The average RMS of turbulent swirl velocity fluctuation inside the piston bowl at TDC of compression is less affected by the induced swirl created by the manifold configurations.

However, further investigations based on combustion and heat release rate analysis is essential for getting a better understanding of the flow inside the cylinder and its effect on the emissions.

\section{References}

Auriemma M., Caputo G., Corcione F.E., Valentino G. and Riganti G. 2003. Fluid-dynamics analysis of the intake system for a HDDI diesel engine by STAR-CD code and LDA technique. SAE Paper No.2003-01-0002.

Borganakke, C., 1981. Predictions of in cylinder swirl velocity and turbulence intensity for an open chamber cup in piston engine. SAE Paper No-810224.

Brandstatter, W., 1985. The effect of inlet port geometry on in-cylinder flow structure. SAE Paper No. 850499.

Chen, A., A. Veshagh and S. Wallace 1998. Intake flow predictions of a transparent DI diesel engine. SAE Paper No.981020.

Chiavola, O. 2001. Integrated modelling of internal combustion engine intake and exhaust system. IMechE. J. Engine Research, Vol. 215, Part A, pp. 495-506.

Dent, J. C., and J. A. Derham 1974. Air motion in a four-stroke direct injection diesel engine. Proc. Instn. Mech. Engrs., Vol. 188, pp. 21-35.

Kim H.-S., Park S.-B., Myung C.-L., Cho K.-M. and Yoon K.-J. 1999. A study of flow characteristics inside the two types of exhaust manifold and CCC system. SAE Paper No. 1999-01-0457.

Margary, R., E. Nino and C. Vafidis 1990. The effect of intake duct length on the in-cylinder air motion in a motored diesel engine. SAE Paper No.90005.

Murakami A., Masatsuguakimoto., Arai M., and Hiroyasu H. 1990. Measurement of turbulent flow in the combustion chamber of D.I diesel engine. SAE Paper No 900061.

Payri, F., Desantes J.M. and Pastor V.J. 1996. LDV measurements of the flow inside the combustion chamber of a 4-valve D.I. diesel engine with axisymmetric piston- bowls. Experiments in Fluids, Vol. 22, pp. 118-128.

Sridhar, G, Paul P.J. and H. S. Mukunda H.S. 2004. Simulation of fluid flow in a high compression ratio reciprocating internal combustion engine. Proc. ImechE, Part A: J. Power and Energy, Vol. 218, No. 6, pp. 403-416.

Taylor III W., Leylek J.H., Tran L.T.., Shinogle R.D. and Jain S.K. 1997. Advanced computational methods for predicting flow losses in intake regions of diesel engines. SAE Paper No. 970639.

Versteeg, H. K., and Malalasekhara W., 1995. An Introduction to Computational Fluid Dynamics: The Finite Volume Methods. Longman group Ltd, London.

Zhu, Y., H. Zhao and N. Ladomatos 2005. Computational fluid dynamics study of the effects of the re-entrant lip shape and ttoroidal radii of piston bowl on a high-speed direct injection diesel engine's performance and emissions. Proceedings of the IMechE, Vol. 219, Part D, Journal of Automobile Engineering. pp. 1011 - 1023.

\section{Biographical notes}

Dr. V. Ganesan is a Professor in the Department of Mechanical Engineering, Indian Institute of Technology Madras, India. He is into teaching and research activities for the last 40 years. His major areas of interests are IC engines and Gas turbines. Dr. Ganesan has published more than 300 papers in national and international journals and conferences. He has attended/conducted many international conferences and has chaired many technical sessions all over the globe.

Dr. Benny Paul is working as an Asst. Professor in Mechanical Engineering Department of M. A. College of Engineering, Kothamangalam, Kerala, India. He has published several papers in various international conferences and journals. His current research interests are on the effect of manifold configuration on flow and combustion inside the cylinder of a direct injection diesel engine.

Received November 2009

Accepted December 2009

Final acceptance in revised form January 2010 